\title{
Influence of genetic variation in fungal endophyte on the third trophic level
}

\author{
J.L. RODSTROM, T. BULTMAN, J. VANDOP, J. LIBRIZZI, L. LONGWELL and T. SULLIVAN. \\ Hope College, Biology Department, Holland, MI, USA \\ bultmant@hope.edu
}

\begin{abstract}
Neotyphodium coenophialum (Ascomycota: Clavicipitaceae) is an endophytic fungus of grasses that produces alkaloids which can have detrimental effects on some insect herbivores, like fall armyworm caterpillars (Spodoptera frugiperda). Alkaloid production can be influenced by fungal genotype. We investigated if endophyte-produced alkaloids might also have effects at the next trophic level. We tested if variation in fungal isolate (three isolates: CS, AR502, AR542; plus a control lacking fungal infection) affected the growth and survival of Euplectrus comstockii (Eulophidae) parasitoids of $S$. frugiperda. Euplectrus comstockii is an ectoparasitoid of caterpillars of many noctuid species. Parasitoid pupal mass was not influenced by fungal isolate $\left(\mathrm{F}_{3,241}=0.61, \mathrm{P}=0.61\right.$, and $\mathrm{F}_{3,190}=0.74, \mathrm{P}=0.53$ for female and male pupae, respectively). In contrast, fungal isolate influenced parasitoid survival $\left(X^{2}=58.3, \mathrm{df}=3, \mathrm{P}<0.0001\right)$. Survival was higher than expected for parasitoids reared from hosts fed plants lacking fungal infection, but was lower than expected for those reared from hosts fed plants infected with AR542 and CS fungal isolates. In contrast, parasitoids reared from hosts fed plants infected with fungal isolate AR502 did not experience higher mortality than expected by chance. Parasitoid mortality mainly occurred during the egg stage. Our results suggest $N$. coenophialum can influence the tritrophic interaction in ways that could be detrimental to the host plant and that this effect is influenced by fungal genotype.
\end{abstract}

Keywords: fall armyworm, Euplectrus, Neotyphodium, novel endophytes, tall fescue

\section{Introduction}

Neotyphodium coenophialum (Ascomycota: Clavicipitaceae) is an endophytic fungus, infecting stems, leaf sheaths and seeds of its grass hosts. The fungus produces alkaloids that can have detrimental effects on some insect herbivores (Clay 1990), like fall armyworm caterpillars (Noctuiidae: Spodoptera frugiperda). Alkaloids include the ergots which affect vertebrates and lolines which mainly influence invertebrates (Siegel \& Bush 1996; Clay \& Schardl 2002). Alkaloid production can be influenced by fungal genotype (Lane et al. 2000). We investigated if endophyte-produced alkaloids might also have effects at the next trophic level, as has been shown for some grass/endophyte systems (Bultman et al. 1997; Omacini et al. 2005). Specifically, we tested if variation in fungal isolate affected the growth and survival of Euplectrus comstockii (Eulophidae) parasitoids of fall armyworm. Euplectrus comstockii is an ectoparasitoid of caterpillars of many noctuiid species.

\section{Methods}

To assess the influence of genetic variation in the endophyte we used seeds of tall fescue (cultivar Jesup) (Bouton et al. 1997) that were infected with the CS strain of $N$. coenophialum; the most common strain (hereafter CS) from pastures in Georgia, USA, or strains AR502 and AR542 isolated from native, wild populations of tall fescue in Europe. Strains AR502 and AR542 were obtained from AgResearch Grasslands, Palmerston North, New Zealand.
Both AR502 and AR542 isolates produce low levels of ergot alkaloids (or produce none at all), but still produce loline alkaloids (Bouton et al. 2002). In contrast, the CS isolate produces ergot alkaloids as well as lolines. With respect to the loline alkaloids, the CS and AR502 isolates produce three loline derivatives (Nformyl loline, $\mathrm{N}$-acetyl loline and $\mathrm{N}$-acetyl norloline) while AR542 produces only N-acetyl norloline (Ball \& Tapper 1999).

Fungal isolates were cultured from parent plants and then introduced into tall fescue plants using inoculation techniques (Christensen et al. 1997). Uninfected seeds were then produced from seed of infected host plants by disinfection via heat treatment (Nott \& Latch 1993); both E- (uninfected) and E+ (infected) seeds were all from the same maternal line. Plants used in the experiment were several generations removed from the heat treatment. Microscopic inspection of 100 seeds of each type showed that all infected lines were at least $90 \%$ infected while E- seeds were $0 \%$ infected. Plants were grown in 10.2 $\mathrm{cm}$ dia pots and fertilised every other week with Peter's liquid fertiliser (20N:20P:20K) at $300 \mathrm{ppm} \mathrm{N}$.

Fall armyworm caterpillars were allowed to feed on clippings of leaf blades from plants within a treatment group from the $2^{\text {nd }}$ to $3^{\text {rd }}$ or $4^{\text {th }}$ instar. Caterpillars ( $n=74$ and $n=91$ for female and male parasitoids reared from them, respectively) were then parasitised by $E$. comstockii parasitoids in the lab. Caterpillars continued to receive food from the appropriate treatment group and were housed separately in petri dishes in an environmental chamber at $26^{\circ} \mathrm{C}$ and a light:dark cycle of $14: 10$. We monitored parasitoid growth and survival, recording sex, pupal mass and successful development to the adult stage. Differences in pupal mass among endophyte isolates were assessed using 1-way ANCOVA, with number of eggs/host and host mass as covariates. One hundred ninety-nine and 245 female and male parasitoids, respectively, were reared. However, we used the mean mass of female and male parasitoids for each host as our replicate (the host and not the individual parasitoid was the sample unit). Differences in survival of developing parasitoids among treatment groups were assessed using contingency table analysis and the Chi-square test.

\section{Results and Conclusions}

Parasitoid pupal mass was not influenced by fungal isolate for both females and males (Fig. 1). In contrast, parasitoid survival from egg to adult was influenced by fungal isolate (Fig. 2). Survival in a total of 444 parasitoids was monitored and found to be higher than expected by chance for adult parasitoids emerging from hosts fed uninfected grass or fungal isolate AR502 and lower than expected for parasitoids emerging from hosts fed the CS or AR542 fungal isolates. Our results only partially follow the known patterns of alkaloid production in the host plants. The CS isolate produces ergots, lolines and peramine (Bouton et al. 2002), which may explain the reduced survival of parasitoids. Isolate AR502 produces three derivatives of lolines ( $\mathrm{N}$-formyl loline, $\mathrm{N}$-acetyl loline, and $\mathrm{N}$-acetyl norloline), while isolate AR542 produces only one (N-acetyl norloline) (Ball \& Tapper 1999). Yet, parasitoid survival was lower on AR542 than on AR502. Differences in loline concentration, which were not addressed in our study, may explain the variation we found in parasitoid survival. 
Figure 1 Pupal mass of Euplectrus parasitoids reared from hosts fed tall fescue with differing endophyte isolates or uninfected ( $E-)$. A. Female parasitoids $\left(F_{3,67}=1.21, P=0.31\right)$. B. Male parasitoids $\left(F_{3,85}=0.76, P=0.52\right)$. Histograms with common letters are not significantly different from one another. Error bars $=1 \mathrm{SEM}$.
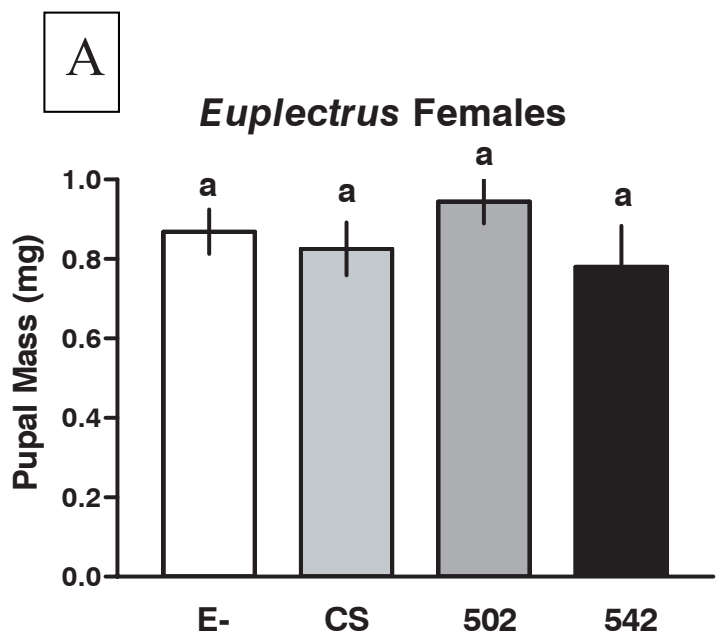

Figure 2 Observed and expected survival of Euplectrus parasitoids when reared from hosts fed tall fescue with differing endophyte isolates or uninfected (E-). Chi-square $=58.34, \mathrm{df}=3, \mathrm{P}<0.0001$.

\section{Euplectrus Survival}

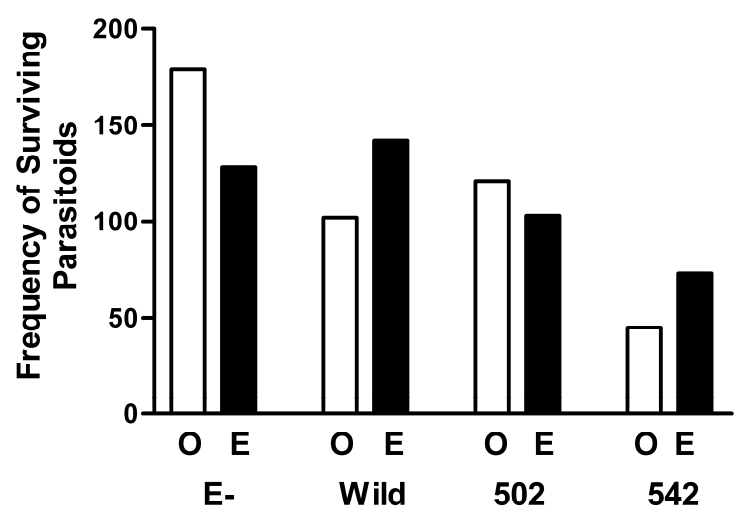

Our results also vary somewhat with previous work in which Euplectrus parasitoids had lower pupal mass when reared from host fed $N$. coenophialum-infected tall fescue, although the cultivar in that study was Kentucky 31 (Bultman et al. 1997). In summary, our study suggests Neotyphodium can influence the tritrophic interaction in ways that could be detrimental to the host plant by reducing survival of the third trophic level.

\section{REFERENCES}

Ball, O.J.-P.; Tapper B.A. 1999. The production of loline aklaloids in artificial and natural grass/endophyte association. pp. 264-269 In: Proceedings of the 51 $1^{\text {st }}$ NZ Plant Protection Conference.Bouton, J.H.; Duncan, R.R.; Gates, R.N.;
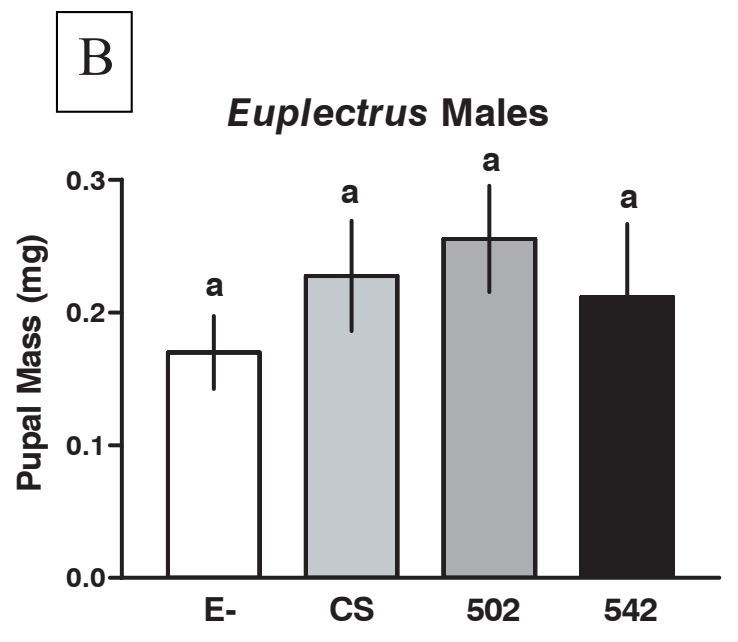

Hoveland, C.S.; Wood, D.T. 1997. Registration of 'Jesup' tall fescue. Crop Science 37: 1011-1012.Bouton, J.H.; Latch, G.C.M.; Hill, N.S; Hoveland, C.S.; McCann, M.A.; Watson, R.H.; Parish, J.A.; Hawkins, L.L.; Thompson, F.N. 2002. Reinfection of tall fescue cultivars with non-ergot alkaloidproducing endophytes. Agronomy Journal 94:567-574.

Bultman T.L.; Borowicz, K.L.; Schneble, R.M.; Coudron, T.A.; Crowder R.J.; Bush, L.P. 1997. Effect of a fungal endophyte and loline alkaloids on the growth and survival of two Euplectrus parasitoids. Oikos 78: 170-176.

Clay, K.; Schardl, C. 2002. Evolutionary origins and ecological consequences of endophyte symbiosis with grasses. American Naturalist 160: S99-S127.Christensen, M.J.; Ball, O.J.P.; Bennett, R.J.; Schardl, C.L. 1997. Fungal and host genotype effects on compatibility and vascular colonization by Epichloë festucae. Mycological Research 101:493-501.Clay, K. 1990. Fungal endophytes of grasses. Annual Review of Ecological Systematics 21: 275-297.Nott, H.M.; Latch, G.C.M. 1993. A simple method of killing endophyte in ryegrass seed, pp. 14-15. In: Proceedings of the $2^{\text {nd }}$ International Symposium on Acremonium/Grass Interactions. Eds. Hume, D.E.; Latch, G.C.M.; Easton, H.S. AgResearch, Palmerston North, New Zealand.

Lane, G.A.; Christensen, M.J.; Miles, C.O. 2000. Coevolution of fungal endophytes with grasses: the significance of secondary metabolites. pp. 341-388. In: Microbial endophytes. Eds. Bacon, C.W.; White, J.F. Jr. Marcel Dekker, New York.

Omacini, M.; Chaneton, E.J.; Ghersa, C.M. 2005. A hierarchical framework for understanding the ecosystem consequences of endophytes-grass symbiosis, pp. 141-162. In: Neotyphodium in Cool-Season Grasses. Eds. Roberts, C.A.; West, C.P.; Spiers, D.E., Blackwell Publ. Ltd. Oxford, UK.

Siegel, M.R.; Bush, L.P. 1996. Defensive chemicals in grassfungal endophyte associations, pp. 81-119 In: Phytochemical diversity and redundancy in ecological interactions. Eds. Barbosa, P.; Romeo, J.T.; Saunders, J.A. Vol. 30 Plenum Press, New York. 